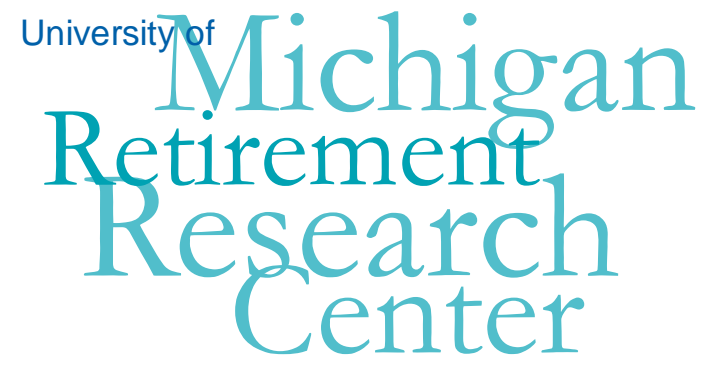

Working Paper

WP 2010-232

\title{
The Effect of the Risk of Out-of-Pocket Spending for Health Care on Economic Preparation for Retirement
}

Michael D. Hurd and Susann Rohwedder

\begin{tabular}{|l|l|}
\hline $\mathrm{M}$ & $\mathrm{R}$ \\
\hline $\mathrm{R}$ & $\mathrm{C}$ \\
\hline
\end{tabular}

Project \#: UM10-18 


\title{
The Effect of the Risk of Out-of-Pocket Spending for Health Care on Economic Preparation for Retirement
}

\author{
Michael D. Hurd \\ RAND and NBER \\ Susann Rohwedder \\ RAND \\ September 2010 \\ Michigan Retirement Research Center \\ University of Michigan \\ P.O. Box 1248 \\ Ann Arbor, MI 48104 \\ http://www.mrrc.isr.umich.edu/ \\ (734) 615-0422
}

\section{Acknowledgements}

This work was supported by a grant from the Social Security Administration through the Michigan Retirement Research Center (Grant \# 10-M-98362-5-01). The findings and conclusions expressed are solely those of the author and do not represent the views of the Social Security Administration, any agency of the Federal government, or the Michigan Retirement Research Center.

\section{Regents of the University of Michigan}

Julia Donovan Darrow, Ann Arbor; Laurence B. Deitch, Bingham Farms; Denise Ilitch, Bingham Farms; Olivia P. Maynard, Goodrich; Andrea Fischer Newman, Ann Arbor; Andrew C. Richner, Grosse Pointe Park; S. Martin Taylor, Gross Pointe Farms; Katherine E. White, Ann Arbor; Mary Sue Coleman, ex officio 


\title{
The Effect of the Risk of Out-of-Pocket Spending for Health Care on Economic Preparation for Retirement
}

\begin{abstract}
After retirement, the primary sources of uncertainty with respect to an individual's economic status are longevity, investment outcomes and out-of-pocket spending on health care. In previous work, we estimated economic preparation for retirement, taking into account the risk of living to an advanced old age and the concomitant risk of running out of resources. But while we accounted for the average level out-of-pocket spending for health care, we did not account for the risk of out-of-pocket spending. In this paper we augment our model for this omission. We find that the risk of out-of-pocket health care spending reduces economic preparation for retirement from about $72 \%$ of persons in the age range 65-69 to about $63 \%$. However, this relatively modest reduction is quite unequally distributed: about $57 \%$ of single persons are adequately prepared when health care spending is not stochastic, but just $44 \%$ when it is. Among single women who are not high school graduates the percentage adequately prepared declines from $33 \%$ to $15 \%$.
\end{abstract}

\section{Authors’ Acknowledgements}

We are grateful for funding from the U.S. Social Security Administration (SSA) via the Michigan Retirement Research Center (UM10-18). We thank the National Institute on Aging for additional financial support for data development (1P01AG08291). Joanna Carroll provided excellent programming assistance. The opinions and conclusions expressed are solely those of the author(s) and do not represent the opinions or policy of SSA or any agency of the Federal Government. 


\section{Introduction}

After retirement, the primary sources of uncertainty with respect to an individual's economic status are longevity, investment outcomes and out-of-pocket spending on health care. A person may be well-prepared if outcomes in these three areas are average. In that case, for example, he or she may have sufficient resources to live to life expectancy or afford average out-of-pocket spending for health care services for the rest of his or her life. But should that person live substantially longer than life expectancy or experience health shocks that require above-average spending on health care, he or she may prematurely deplete available resources.

In previous work, we estimated economic preparation for retirement, taking into account the risk of living to an advanced old age and the concomitant risk of running out of resources (Hurd and Rohwedder, 2008a). Our method was to estimate empirical lifecycle consumption paths on the basis of panel data on total spending. The data came from the Consumption and Activities Mail Survey (CAMS)—a random subsample of HRS households. Our estimations of life-cycle consumption paths accounted for age, sex, martial status, and education. We used the latter as a proxy for variation in mortality risk, which influences the shape of life-cycle consumption paths. We asked whether, in a sample of 65-69 year-olds, economic resources could support with high probability the life-cycle consumption path anchored at the initial level of consumption until the end of life.

This prior work explicitly accounted for mortality risk. Doing this is important for at least three reasons: First, economic resources only have to last for a finite number of years, which means that wealth can be spent down. In other words, income alone is not an adequate measure of economic preparation for retirement: wealth also needs to be taken into account. Second, most people enter retirement as married persons, but eventually one of the spouses dies. The surviving spouse has reduced spending needs, so that the total required lifetime resources will be less than those projected from the spending of a couple. Third, because the well-to-do survive longer than the poor, their resource requirements will be relatively larger. Our research took these aspects of 
mortality risk into account via simulation, where the probability of dying depended on age, marital status, sex, and education.

We found that a substantial majority of those just past the usual retirement age are adequately prepared for retirement, in that they will be able to finance a path of consumption that begins at their current level of consumption and then follows an agepattern similar to that of current retirees. This is not true, though, for all groups in the population. In particular, almost half of singles without a high school education will be likely to be forced to reduce consumption. Couples are much better prepared than singles. But because of taxes, a substantial number of married college graduates will also have to reduce consumption.

The model we used for this work did not account for health-care spending risk, however. Although our spending levels included mean spending on health care and the slopes of the consumption paths depended on changes in mean spending with age, the model did not permit a household to experience an individual shock to health care spending that would deplete its assets. To investigate this factor, we initiated a second line of research: estimation of the risk of out-of-pocket spending for health-care costs. The Health and Retirement Study (HRS) 2002 and 2004 contained some reports of very large amounts of out-of-pocket spending (Hurd and Rohwedder, 2009). Such out-ofpocket expenses will have a profound influence on saving. If these are the risks that people actually face and people know that these are the risks, they will aim to accumulate considerable buffer stock savings to guard against such costs. To the extent that households have not accumulated this level of wealth, they are not adequately prepared financially for retirement.

The goal of this paper is to explicitly account for the risk of large out-of-pocket spending on health care. Our method is similar to that of our previous paper, except that individuals and households are subject each year to a random expenditure on health care. We draw these spending shocks from the empirical distribution of out-of-pocket spending in HRS 2008. Because they can be large, in some cases, they can reduce the wealth of an individual or household to zero. The increase in the variance in spending, rather than an increase in the mean, will reduce the percentage of persons and households adequately prepared for retirement. 


\section{Data}

Our analyses are based on data from the HRS and data from the CAMS. The HRS is a biennial panel. Its first wave was conducted in 1992. The target population was the cohorts born in 1931-1941 (Juster and Suzman, 1995). Additional cohorts were added in 1993 and 1998, so that in 2000 the HRS represented the population from the cohorts of 1947 or earlier. In 2004, more new cohorts were added, making the HRS representative of the population 51 or older.

In September 2001, CAMS wave 1 was mailed to 5,000 households selected at random from households that participated in HRS 2000. In couples households, it was sent to one of the two spouses at random. The fact that the CAMS sample was drawn directly from the HRS 2000 population allows the CAMS data to be linked to the vast amount of information collected in prior waves of the HRS on the same individuals and households. In September 2003 and October 2005, CAMS waves 2 and 3 were sent to the same households. ${ }^{1}$ The structure of the questionnaire was almost the same in each of these two waves, to facilitate panel analysis. In this paper, we will use CAMS data from waves 1,2 , and 3 .

CAMS asked respondents about their spending in each of 32 categories. This elicits almost the totality of spending according to the Consumer Expenditure Survey. The rates of item nonresponse in CAMS were small. Some values could be imputed to zero with considerable confidence, due to the information in the linked HRS data. For example, some homeowners (as recorded in the HRS) did not report a value in CAMS for “rent”; those responses were imputed to zero. ${ }^{2}$ The resulting spending levels are close to totals from the Consumer Expenditure Survey (CEX) for the age groups 55-74. ${ }^{3}$ CAMS shows higher spending levels among those 75 or over. There is no apparent reason for seeing this difference in this age group, but not in the younger age group. For the HRS

\footnotetext{
${ }^{1}$ CAMS 2005 included, in addition, a sub-sample of the newly added cohort of the Early Baby-Boomers that was first recruited into the HRS sample as part of the HRS 2004 core survey.

${ }^{2}$ See Hurd and Rohwedder (2005).

${ }^{3}$ The CEX collects the most detailed and comprehensive information on total spending by households.
} 
population, however, we believe the higher CAMS totals are more accurate because they provide a better fit to observed rates of wealth decumulation at older ages. ${ }^{4}$

\section{Methods}

Our approach relies on simulating consumption paths over the remaining life cycle for a sample of households observed shortly after retirement. For this purpose, we need two things: first, the initial level of consumption, which we observe directly in the CAMS data; and second, the slope of the consumption path, which we estimate from panel transitions observed in CAMS wave 1 to 2 and CAMS wave 2 to 3.

We construct life-cycle consumption paths for each household. We begin with the observed consumption level at retirement age. We then apply the observed rates of change to trace out a life-cycle path whose slope is given by the estimated rates of change. Whereas a model based on a particular utility function would specify that the slope of the consumption path depends on the interest rate, the subjective time-rate of discount, mortality risk, and utility function parameters, we instead estimate these slopes directly from the data. Practically all model estimation uses the constant-relative-riskaversion utility, which specifies that the slope of log consumption is independent of the level. But observed consumption paths do not necessarily have that shape and in this study, we do not impose it on them. Accordingly, while our estimations are model-based in that we use the framework of lifetime utility maximization, they are essentially nonparametric, in that we allow the data to directly determine the consumption path.

Single persons We first consider the case of single persons. The consumption path is anchored at the initial post-retirement consumption level and follows the path given by the slopes of consumption paths that we have estimated from the CAMS panel data on single persons. We take into account uncertainty about the length of life by running a number of simulations of the life-cycle path for each person. In each simulation, a person will survive from one period to the next with some probability. Someone may have the resources to finance his or her consumption for many years, but not enough to do so should he or she live to an extreme old age. A good definition of

\footnotetext{
${ }^{4}$ When compared with after-tax income in the HRS, the lower levels of spending in CEX imply that single persons accumulate wealth, whereas in panel, they decumulate wealth (Hurd and Rohwedder, 2008b).
} 
adequate preparation should be that resources are ample enough to sustain the consumption path until advanced old age, where the probability of survival is very small. We count the fraction of the simulations in which an individual dies before running out of wealth. If that fraction is high (say 95\%), we conclude the person is adequately prepared for retirement.

The evaluation involves comparing economic resources with needs as reflected in initial consumption. We do this calculation for all single persons in our CAMS sample in their early retirement years. Someone with a moderate level of pre-retirement consumption could sustain consumption after retirement with a moderate level of Social Security benefits, some pension income, and a moderate amount of wealth. Someone with low pre-retirement consumption may only need Social Security and a small amount of savings. These requirements are likely to differ substantially from what would be required to sustain consumption after retirement at the pre-retirement income level.

We account for consumption of health-care services on average in the CAMS data: This category of consumption is part of the CAMS measurement; consequently, it helps us determine a single person's initial total level of consumption and the rate of change in consumption with age. If there were no spending risk, out-of-pocket spending for health care would need no further treatment. But because spending risk is a factor, a single person's actual consumption of health-care services will differ from the average level by a spending shock that has an expected value of zero, but could be quite large. We construct that shock from HRS data on out-of-pocket spending for health-care services.

Couples For couples, our basic method is similar. However, the consumption path a couple follows while both spouses survive will differ from the consumption path of single persons, so we estimate it separately from the CAMS data. The couple will follow that consumption path as long as both spouses are alive, and then the surviving spouse will switch to a single person's consumption path. We estimate the shape of the single's path from the CAMS data. But the surviving spouse's level of consumption will depend on returns-to-scale in consumption by the couple. Upon the death of one spouse, the surviving spouse will reduce consumption to the level specified by the returns-toscale parameter. We assume a returns-to-scale parameter consistent with the literature 
and with practice. For example, the poverty line specifies that a couple with 1.26 times the income of a single person who is at the poverty line will also be at the poverty line. This implies that consumption spending by the surviving spouse should be $79 \%$ of spending by the couple in order for the surviving spouse to achieve a comparable level of effective consumption after widowing. ${ }^{5}$

Having determined the surviving spouse's consumption path, we find the expected present value of consumption for the lifetime of the couple and the surviving spouse. We compare population averages of the expected present value of consumption with average resources at retirement to find whether the cohort can finance the expected consumption path. We also determine the fraction of households that can finance their expected consumption path with, say, a 95\% probability, and by how much a household would have to adjust consumption to minimize the chances of running out of wealth towards the end of the life cycle.

\section{Differential Mortality}

A large body of literature on the gradient between socioeconomic status (SES) and health documents that individuals with high SES, such as higher levels of education, live longer than those with low SES. Because households are not fully annuitized, longlived households have to be prepared to finance consumption over a longer remaining time horizon. We take this into account in our simulations by applying survival probabilities that differentiate by education, as well as by age, sex, and marital status.

Given the extended time horizon to which they are subject, high SES households may also follow different consumption paths than low SES households. Economic theory predicts a flatter consumption path when mortality risk is lower. Consequently, we also stratify by education when estimating the consumption paths for singles and couples.

We obtain our estimates of differential mortality from seven waves of HRS data spanning the years 1992 to 2004 . We estimate the probability of survival at time $t+1$ conditional on being alive at time $t$, pooling the six transitions we observe in the HRS. The logit model yields the estimates shown in Table 1 for separate estimations for males and females as a function of age, marital status, and education. For men and women

\footnotetext{
${ }^{5}$ Our results are not sensitive to the returns-to-scale parameter.
} 
alike, the survival odds increase with more education, but the profiles are different: For men, there is a large gain from completing college-much larger than the gain for women. Among males, the odds for college graduates of surviving between waves are 79\% higher than the odds for high school dropouts.

From these estimates, we construct survival curves by sex, marital status, and education. We then normalize these to life tables so that the average survival probability, given age and sex, equals that given in the life tables.

\section{Estimation of consumption path}

Because survival differs by age, sex, and education, the slope of the consumption path should vary by those characteristics. Therefore, we estimate the model

$$
\frac{c_{t+1}-c_{t}}{c_{t}}=\alpha_{i}+\beta_{j}+\theta_{k}+u
$$

separately for single persons and for couples, where $i$ indicates age category, $j$ indicates education category, and $k$ indicates sex. For singles, we have five age categories (65-69, 70-74, 75-79, 80-84, and 85 or over). We observe 2,503 consumption transitions among singles 65 or older between the four waves of CAMS. For couples, we have just four age categories for the male spouse because of small sample size in the top age category. In addition, we enter an indicator variable for whether the female is younger than her spouse by five or more years. We observe 4,913 consumption transitions among couples, where one spouse is age 66 or older and the other is at least age 62 or older. We also have four education categories: less than high school, high school, some college, and college graduate. We estimate by median regression, because observation error on consumption produces large outliers in the left-hand variable—which makes OLS estimates unreliable.

Table 2 has the fitted values of the percentage change in consumption by couples. The rate of change of consumption is small and negative, and becomes smaller with age. There is little variation with education even though, conditional upon age, education is an indicator for longevity. ${ }^{6}$ According to economic theory, the rate of decumulation should

\footnotetext{
${ }^{6}$ We used the following algorithm to determine whose education to use in the case of couples: if one of the two spouses is younger than 66 then we used the education of the older spouse; if both spouses are 66 or older then we chose at random whose education would enter the estimation.
} 
be smaller when the spouse is substantially younger. We account for this with an indicator variable for when the wife is younger than the husband by more than five years; however, the effect is the opposite of the theoretical prediction.

Consumption by single persons declines at a greater rate than consumption by couples. The rate accelerates with age, becoming quite high at advanced old age (Table 3). Furthermore, consumption declines at a greater rate among the less educated (in line with the theoretical predictions).

\section{Taxes}

Taxes, which include Social Security contributions, influence economic preparation for retirement via four routes: First, federal and state taxes must be paid on ordinary income, such as earnings, capital income, and pension income. Second, Social Security contributions must be paid on earnings. Third, Social Security income is only partially counted as taxable income; the fraction depends on the level of other taxable income and the amount of Social Security income. Fourth, withdrawals from taxadvantaged accounts such as IRAs are taxed. We account for these taxes and governing provisions in a somewhat simplified manner that nonetheless addresses all four of these influences. ${ }^{7}$

\section{Measurement of Out-of-Pocket Spending on Health Care}

When we compared the level and distribution of out-of-pocket spending on health care in HRS 2004 with similar measures in the Medical Expenditure Panel Survey (MEPS) and the Medicare Current Beneficiary Survey (MCBS), we found that mean outof-pocket spending in the HRS was about $60 \%$ greater than in the MCBS or MEPS (which are similar to each other). But HRS medians were practically the same as in MCBS and in MEPS (Hurd and Rohwedder, 2009). The discrepancy in means is due to some very large values in HRS. For example, the $99^{\text {th }}$ percentile of spending in 2004

\footnotetext{
${ }^{7}$ We use standard deductions and estimate the relationship between federal and state income taxes for each household based on the NBER tax calculator, TAXSIM. We use this relationship to estimate state taxes. We assume that withdrawals from tax-advantaged accounts will be made when spending exceeds income, and that the amount withdrawn will be proportional to the value of the tax-advantaged account relative to the value of post-tax accounts. We also account for the minimum required withdrawal after the age of 70 and a half.
} 
HRS was \$24,600 expressed in 2003 prices. In contrast, the $99^{\text {th }}$ percentile in 2003 MCBS was \$11,400 and \$9,300 in 2003 MEPS. The risk of out-of-pocket spending for health care is substantially greater in HRS than in MCBS or MEPS. We determined in Hurd and Rohwedder (2009) that the main source of the difference is in the measurement of spending on prescription drugs.

Out-of-pocket spending on prescription drugs is particularly difficult to measure in a household survey because of the heterogeneity in purchasing patterns. Some people take a particular medication on a regular monthly basis; for them, a single question about monthly spending will (when annualized) give a good estimate of yearly spending. Other people take drugs only infrequently in response to a health event; for them, spending may be substantial during a health incident. Annualizing spending from a particular month will result in no spending among those not experiencing a health incident during the queried month — which would the majority, and a very large value among the small group that happened to have a health incident during the queried month. The population average will be accurate, but the process will generate large outliers.

The HRS in 2004 asked those who say they "regularly take prescription medications" the following question about costs: "On average, about how much have you paid out-of-pocket per month for these prescriptions in the last two years?" In order to convert this monthly amount to a two-year measure one would multiply the monthly amount by 24. Error can be introduced if respondents report actual spending in the last month or two, even though spending is episodic. More serious error would occur if a respondent reported a yearly, rather than a monthly amount. It is likely to be difficult for a respondent to remember the details of spending over a 24-month period and be able to report an average monthly amount.

Because both MCBS and MEPS devote a considerable amount of effort to measuring out-of-pocket spending on prescription drugs, one could reasonably presume that the measurements they provide are more accurate than in the HRS. However, for our purposes, it is highly desirable to be able to use data from the HRS because of its linkages to respondents' personal and household characteristics. We find a solution to this dilemma in modifications made in more recent waves of the HRS. 
In 2006, HRS made a small change in the question sequence about spending on prescription drugs. After posing the primary question, the interviewer would ask respondents whether there were some months in which they spent much more than the amount they had reported. When asking this follow-up question, the interviewer would read back the reported amount and give respondents the opportunity to correct their initial report. Apparently this (small) additional question resulted in a considerable drop in mean spending on prescription drugs from what the trend values drawn from HRS 2000, 2002 and 2004 (and what we know about risk in health care costs) suggested:

Two-year out-of-pocket spending for prescription drugs, persons age less than 65

\begin{tabular}{ccc}
\hline Year & Mean & Median \\
\hline 2000 & 1,313 & 600 \\
2002 & 2,448 & 720 \\
2004 & 3,327 & 1,080 \\
2006 & 1,771 & 960 \\
\hline
\end{tabular}

The mean in 2006 was about half of the mean in 2004 — even though out-ofpocket spending costs in the HRS had increased by very large ratios from 2000 to 2002 and 2002 to 2004. The introduction of Medicare Part D in 2006 was not responsible for the observed decline in the table above, because Medicare Part D is a program for the population age 65 or older, but the table shows statistics for the population younger than 65.

Given this change in the HRS questionnaire in 2006 and the advantages of using data from the HRS, we take HRS out-of-pocket spending from the 2008 wave to be an accurate representation of the distribution of out-of-pocket spending actually faced by HRS respondents and households. ${ }^{8}$

\footnotetext{
${ }^{8}$ Although it would be desirable to have more observations on out-of-pocket spending as would be obtained from combining HRS 2008 with earlier waves, the discrepancies are too large to combine them.
} 


\section{Results}

Because we want to observe Social Security and pension income, we select a sample of respondents who have recently retired and are old enough to be likely to be receiving Social Security if they are eligible. For single persons, we select individuals who are 66-69. We select couples that meet several criteria: one spouse is 66, 67, 68, or 69 , and the other is 62 or older; they were respondents in CAMS wave 1, 2, 3, or 4; and they were a couple in the HRS surrounding waves. We include the age restriction on the younger spouse because spouses younger than 62 would not yet be receiving Social Security benefits. This would cause us to miss a significant fraction of retirement resources.

We perform 20 simulations of the consumption and wealth paths of each married person in the age range 66-69. By consumption, we mean the couple's consumption as long as both spouses survive and then the consumption by the survivor. Although we begin with 886 households as shown in Table 2, we only have 1092 married persons who are age eligible (66-69), the other spouses being outside the specified age range. The economic circumstances of the 1092 age-eligible persons enter the tables. In these simulations, we use the poverty line returns-to-scale and assume that the annuity of the survivor is 0.67 times the annuity of the couple.

Tables 6 and onward show the results of the simulations, incorporating taxes, differential mortality by education level, and differential rates of change in consumption by education level. Because we are interested in the fraction of individuals that run out of resources at the end of the lifecycle, we have arranged all subsequent tables at the individual level: They show the results for 66-69 year olds living in couple households and single households at baseline, as well as their characteristics. Our initial results do not include health-spending shocks; these we will report later in a comparative context.

Table 4 shows that in $84 \%$ of the simulations, the surviving spouse dies with positive wealth and those with more education are more likely to have positive wealth at death. Initial average wealth, the average present value of earnings, and the average present value of annuities for couples total about $\$ 1.2$ million. The present value of consumption is about $\$ 540$ thousand; the present value of taxes is $\$ 190$ thousand. 
Average economic resources exceed average spending (including taxes) by about $\$ 470$ thousand. We call this value “excess” wealth.

At least on average, couples are well prepared financially for retirement. The median of the household-level amount of excess wealth is about \$252 thousand, indicating that the household of the median person is also well prepared. As would be expected, the measures increase strongly with education, but even those persons with less than a high school education are, at the median, adequately prepared.

For singles, the results are much less optimistic (Table 5). In 62\% of the simulations, wealth is positive at death. Median excess wealth is just \$51 thousand, and in the lowest education band it is essentially zero.

The fraction of simulations in which wealth is positive at death does not provide the risk of any individual or household outliving resources. For example, the $62 \%$ in the case of single persons would be achieved if every single person had a $62 \%$ chance or if $62 \%$ of single persons had a $100 \%$ chance of dying with positive wealth and $38 \%$ had no chance. To assess this risk at the individual level, we use a metric based on the fraction of simulations for which either an individual in a couple or a single person dies with positive wealth. In this metric, we say that the individual is adequately prepared if the chances of dying with positive wealth are 95\% or greater.

Table 6 shows that overall, about $80 \%$ of married persons are adequately prepared. The average for males is lower than that for females-somewhat surprising because husbands typically die before wives and accordingly, are more likely to die before assets have been depleted. However, it should be kept in mind that there are 886 households in our sample, yet just 1092 individuals. The implication is that in $62 \%$ of these households, only one of the spouses meets our selection criteria for being age 6669. Consequently, the males and females generally come from different households. These different households have different economic resources and have chosen different initial consumption levels, which may account for the lower average among males than females.

Among singles, about 51\% are adequately prepared financially for retirement (Table 7). Here there were significant differences by sex: In the lowest education band of singles, only 39\% of women are adequately prepared, compared with $67 \%$ of men. 
Combining the results for men and for women, we find that, according to this metric, about $72 \%$ of persons are adequately prepared financially for retirement. There is a sharp variation by educational status: only $56 \%$ in the lowest education category of men and women combined, compared with $80 \%$ in the highest.

We put consumption shortfalls or excesses in a probabilistic framework. As a rough utility indicator of the magnitude of a shortfall, we say that financial preparation is adequate if a reduction in consumption of $15 \%$ would permit the (reduced) consumption path to be financed. In this sense, we say that an individual is inadequately prepared if he or she would need to reduce initial household consumption by $15 \%$ or more to keep the chance of running out of wealth to $5 \%$ or less. Table 8 shows that, in these terms, among married persons, about $85.6 \%$ are adequately prepared, and females are slightly more likely to be prepared than men. Even among high school drop-outs, about $76 \%$ are adequately prepared. Among singles (Table 9), in contrast, the overall rate is $66 \%$. A particularly inadequately prepared group among singles is females in the lowest education category: Just $43 \%$ are adequately prepared.

\section{Accounting for health spending shocks}

In each time period, we make a random draw from the observed distribution of out-of-pocket spending in HRS 2008. After normalizing it to have mean zero, we add it to spending by the single person or couple in that period. If the normalized out-of-pocket spending is below average, the shock will increase wealth from its predicted path; if the normalized spending is above average the shock will reduce wealth. Should the shock be large enough to reduce wealth to zero, that person or household will have run out of wealth before the end of life. For theoretical and empirical reasons in our simulations we have disaggregated by sex, marital status, age and education, and we also do so for health spending shocks: the distribution from which the spending shock is drawn depends on those same personal characteristics. On average spending with the shocks will be the same as spending in the absence of the shocks as long as wealth is positive. However, the shocks will increase the variance of predicted wealth. Persons with negative shocks will die with more wealth than previously. Some persons with positive shocks will have 
their wealth driven to zero before they die and so will not be adequately prepared for retirement. ${ }^{9}$

Table 10 shows the percentage of married persons that have a high probability of dying with positive wealth in the absence of health spending shocks, which is copied from Table 6, and the percentage that have a high probability in the presence of health spending shocks. Overall the health spending shocks reduced economic preparation for retirement among couples by three percentage points. The reduction is large among the less-well educated because they had a relatively smaller amount of wealth to buffer against shocks. Economic preparation among females in the lowest education category is estimated at just $65 \%$.

Among singles the effect of health care spending shocks is substantially greater because of a lower level of wealth against which to buffer the shocks (Table 11). Overall economic preparation fell by 9.3 percentage points and among women in the lowest education category it fell by 13 percentage points to just $19.8 \%$.

Table 12 has results for couples when the metric for economic preparation is based on a reduction in consumption of less than 15\%, and table 13 has similar results for single persons. The reductions in the percentage of persons adequately prepared are similar to those based on wealth but the levels of economic preparation are higher. But even allowing a reduction in spending of $15 \%$, just $30.5 \%$ of single women in the lowest education category are adequately prepared. Thus a substantial majority will have to reduce their consumption by more than $15 \%$ at some point in their lifetimes.

\section{Serial correlation in out-of-pocket spending for health care}

People who have chronic conditions are likely to have greater than average spending on heath care each year, which induces serial correlation in out-of-pocket spending. Serial correlation increases the likelihood that someone will have several successive years of high spending, and, hence, that his or her wealth will be spent.

At the household level we estimate a model of out-of-pocket spending by marital status specified as follows:

\footnotetext{
${ }^{9}$ We assume that if wealth is driven to zero by a spending shock, that person or household will consume at the level of annuity income. This implicitly assumes that future health care spending shocks are paid for by a public program such as Medicaid.
} 


$$
\ln \left(s_{i j k, t}\right)=\left(\alpha_{i}+\alpha_{j}+\alpha_{k}\right)+\left(\beta_{i}+\beta_{j}+\beta_{k}\right) \ln \left(s_{i j, t-1}\right)
$$

where $i$ indexes age, $j$ indexes sex, and $l$ indexes education. Thus the correlation between spending at $t-1$ and $t$ will depend in an additive manner on those personal characteristics. The categories of age and education follow those we have used in the specifications for the consumption trajectories and for mortality.

We estimated this model on MCBS 2004 and 2005. ${ }^{10}$ We chose MCBS for several reasons. First, we could not use HRS because our model has one-year transitions, but HRS is a two-year panel. Second, MEPS specializes in measuring health care spending including out-of-pocket spending, but we could not use it because it does not cover the institutionalized population. Third, MCBS spends considerable amount of interviewing resources to collect out-of-pocket spending data, and it compares well with MEPS for the noninstitutionalized population. It does cover the institutionalized population.

Table 14 shows the estimated coefficients from the regression of out-of-pocket spending in 2005 on out-of-pocket spending in 2004 for married persons. There is strong persistence in spending: among couples from the reference group 54\% of spending in 2004 is carried over to 2005. Although the increase is not monotonic in age the percentage carried over tends to increase with age so that in the age band 80 or older $67 \%$ is carried over. This is likely due to the increase in chronic conditions. Table 15 has similar results for single persons. About $67 \%$ of spending is carried over from one year to the next for the reference group. There is some variation with personal characteristics, but it is small and not statistically significant.

To simulate serially correlated out-of-pocket spending we note that in a simple model of serial correlation

$$
u_{t}=\rho u_{t-1}+v_{t}
$$

where the $v_{t}$ are i.i.d. $\left(0, \sigma^{2}\right)$. Then the $u$ are i.i.d. $\left(0, \sigma^{2} /\left(1-\rho^{2}\right)\right.$. In our spending data from HRS 2008 we have observations on the $u$ and so we can calculate the variance of $u$ and the variance of $v$ as $V(v)=V(u)\left(1-\rho^{2}\right)$.

\footnotetext{
${ }^{10}$ We could not use HRS because of its two-year periodicity, but our model has one-year transitions.
} 
Let $s_{a t}$ be actual out-of-pocket spending as observed in HRS, and let $s_{t}$ be spending assigned to a person. Then we can simulate the estimated serial correlation and preserve the distribution of out-of-pocket spending by drawing from the actual distribution in the first period of the simulation, $s_{a 1}$ and assigning that to out-of-pocket spending in period 1: $s_{1}=s_{a 1}$. In the next period we draw from the actual distribution, $S_{a 2}$ and then assign out-of-pocket $s_{2}$ as

$$
s_{2}=\rho s_{1}+s_{a 2} \sqrt{1-\rho^{2}}
$$

Then $V\left(s_{2}\right)=V\left(s_{a}\right)$. We continue in this manner

$$
s_{t+1}=\rho s_{t}+s_{a t+1} \sqrt{1-\rho^{2}}
$$

This ignores that we want to only modify wealth by health-care spending shocks, that is, deviations from means. The shock in any period would be

$$
s_{t}-\bar{s}_{a}
$$

where $\bar{s}_{a}$ is the mean of spending in the HRS. It does not have a $t$ subscript because we are always drawing from the same distribution (2008 HRS).

The preceding applies to each group defined by age, education, sex and marital status: each group has its own distribution of $s_{a}$ and its own value of $\rho$. We use the results in Tables 14 and 15 to calculate $\rho$ for each individual.

Table 16 compares the results for married persons when there is serial correlation with results when there is no serial correlation.

Table 17 compares the results for singles when there is serial correlation with results when there is no serial correlation. Overall the percentage adequately prepared declined from $47.6 \%$ to $43.9 \%$ based on the criterion of dying with positive wealth. However, there are substantial differences based on education and sex. With serial correlation, the percentage adequately prepared among those lacking a high school education declined by about five percentage points. Among such females, just 15.3\% were adequately prepared. This reduction is in sharp contrast with the findings for college graduates where there was no change associated with a serial correlation in outof-pocket spending on health care. 


\section{Conclusions}

Stochastic variation in out-of-pocket spending for health care changes quite sharply the percentage of single persons adequately prepared for retirement. When there are no shocks, $56.8 \%$ are adequately prepared. With serially correlated health shocks, just 43.9\% are adequately prepared — even though average out-of-pocket spending on health care does not change (by design). The difference for females specifically is even larger: $58.3 \%$ with no shocks versus $38.6 \%$ with. For females without a high school degree, just $15.3 \%$ died with positive wealth in the simulations that used both health-spending shocks and serially correlated spending. This is compared with $32.8 \%$ when health spending was not stochastic.

The effects on married people are not nearly as large because many couples have wealth substantially in excess of what is required to deal with most health-care spending shocks. In this sample, the percentage of those adequately prepared declined from $80.3 \%$ with no shocks, to $73.3 \%$ with.

When we average all 1,725 persons in our overall sample, both single and married, the percentage adequately prepared is $71.7 \%$ when out-of-pocket spending does not have a stochastic component. But when out-of-pocket spending is stochastic (with the distribution recorded in HRS 2008) and when spending is serially correlated (as estimated from MCBS 2004 and 2005), the percentage of those who are financially prepared for retirement declines by 9.2 percentage points to $62.5 \%$. 


\section{REFERENCES}

Hurd, Michael D. and Susann Rohwedder, 2008a, “The Adequacy of Economic Resources in Retirement,” Michigan Retirement Research Center Working Paper WP 2008-184, September.

Hurd, Michael D. and Susann Rohwedder, 2008b, "Wealth Change and Active Saving at Older Ages,” presented at the January 2009 annual meetings of the American Economic Association, RAND typescript.

Hurd, Michael D. and Susann Rohwedder, 2009, “The Level and Risk of Out-of-Pocket Health Care Spending,” Michigan Retirement Research Center Working Paper 2009-218, September. 
Table 1

Logit estimates of survival based on seven waves of HRS

\begin{tabular}{lrrrr}
\hline & \multicolumn{2}{c}{ Males } & \multicolumn{2}{c}{ Females } \\
\cline { 2 - 5 } Covariates & Odds ratio & P-value & Odds ratio & P-value \\
\hline & 1.31 & 0.00 & 1.26 & 0.00 \\
married & -- & -- & -- & -- \\
less than high school & 1.15 & 0.02 & 1.3 & 0.00 \\
high school & 1.18 & 0.02 & 1.46 & 0.00 \\
some college & 1.79 & 0.00 & 1.59 & 0.00 \\
college graduate & & & & \\
\hline
\end{tabular}

Reference group: single, less than high school

Source: Authors' calculations

Table 2

Couples. Estimated one-year change in consumption (percent), real

\section{Education}

\begin{tabular}{|c|c|c|c|c|c|c|}
\hline $\begin{array}{l}\text { Male Age - } \\
\text { Female Age }\end{array}$ & Male Age & $\mathrm{N}$ & $\begin{array}{l}\text { Less than } \\
\text { high-school }\end{array}$ & $\begin{array}{l}\text { High-school } \\
\text { graduate }\end{array}$ & $\begin{array}{l}\text { Some } \\
\text { college }\end{array}$ & $\begin{array}{c}\text { College } \\
\text { and above }\end{array}$ \\
\hline \multirow{5}{*}{$<5$ years } & 62-64 & 104 & 1.22 & 0.96 & 0.82 & 0.82 \\
\hline & $65-69$ & 1,344 & -0.74 & -1.00 & -1.14 & -1.14 \\
\hline & $70-74$ & 1,107 & -1.47 & -1.73 & -1.87 & -1.87 \\
\hline & $75-79$ & 715 & -1.57 & -1.83 & -1.96 & -1.96 \\
\hline & $80+$ & 409 & -1.75 & -2.01 & -2.14 & -2.14 \\
\hline \multirow[t]{4}{*}{$5+$ years } & $65-69$ & 157 & -2.28 & -2.54 & -2.68 & -2.68 \\
\hline & $70-74$ & 407 & -3.01 & -3.27 & -3.41 & -3.41 \\
\hline & $75-79$ & 329 & -3.10 & -3.36 & -3.50 & -3.50 \\
\hline & $80+$ & 341 & -3.28 & -3.54 & -3.68 & -3.68 \\
\hline
\end{tabular}


Table 3

Single persons. Estimated one-year change in consumption (percent), real

\begin{tabular}{|c|c|c|c|c|c|}
\hline \multirow[b]{2}{*}{ Female Age } & \multirow[b]{2}{*}{$\mathrm{N}$} & \multicolumn{4}{|c|}{ Education } \\
\hline & & $\begin{array}{c}\text { Less than } \\
\text { High- } \\
\text { school }\end{array}$ & $\begin{array}{c}\text { High-school } \\
\text { graduate }\end{array}$ & $\begin{array}{c}\text { Some } \\
\text { college }\end{array}$ & $\begin{array}{c}\text { College and } \\
\text { above }\end{array}$ \\
\hline $65-69$ & 514 & -3.69 & -2.73 & -2.29 & -1.27 \\
\hline $70-74$ & 451 & -3.09 & -2.13 & -1.69 & -0.67 \\
\hline $75-79$ & 368 & -4.10 & -3.15 & -2.70 & -1.68 \\
\hline 80-84 & 359 & -7.00 & -6.05 & -5.60 & -4.58 \\
\hline 85 or over & 356 & -3.77 & -2.81 & -2.37 & -1.34 \\
\hline \multicolumn{6}{|l|}{ Male Age } \\
\hline 65-69 & 145 & -3.37 & -2.41 & -1.97 & -0.95 \\
\hline $70-74$ & 94 & -2.77 & -1.81 & -1.37 & -0.34 \\
\hline $75-79$ & 84 & -3.78 & -2.82 & -2.38 & -1.36 \\
\hline 80-84 & 78 & -6.68 & -5.72 & -5.28 & -4.26 \\
\hline 85 or over & 54 & -3.45 & -2.49 & -2.05 & -1.02 \\
\hline
\end{tabular}

Table 4

Married persons, initial wealth, present value of earnings, annuities, and consumption, and excess wealth, (thousands 2004\$)

\begin{tabular}{lrrrrrrrr}
\hline & $\mathrm{N}$ & $\begin{array}{r}\% \\
\text { positive }\end{array}$ & $\begin{array}{r}\text { mean } \\
\text { initial } \\
\text { wealth }\end{array}$ & $\begin{array}{r}\text { mean PV } \\
\text { of future } \\
\text { earnings }\end{array}$ & $\begin{array}{r}\text { mean PV } \\
\text { annuities }\end{array}$ & $\begin{array}{r}\text { mean PV } \\
\text { consumption }\end{array}$ & $\begin{array}{r}\text { mean } \\
\text { excess } \\
\text { wealth }\end{array}$ & $\begin{array}{r}\text { median } \\
\text { excess } \\
\text { wealth }\end{array}$ \\
\cline { 2 - 9 }$<$ high-school & 187 & 75.5 & 284.6 & 14.1 & 265.6 & 323.5 & 196.5 & 123.6 \\
High-school & 474 & 84.8 & 499.2 & 16.5 & 393.5 & 438.8 & 365.4 & 234.8 \\
Some college & 223 & 85.7 & 1024.5 & 22.6 & 475.3 & 596.2 & 651.7 & 292.4 \\
College & 208 & 88.5 & 1406.7 & 56.7 & 652.9 & 888.9 & 783.3 & 494.3 \\
All & 1,092 & 84.1 & 742.6 & 25.0 & 437.7 & 536.9 & 474.6 & 252.3 \\
\hline
\end{tabular}

Source: Authors' calculations.

Note: $\mathrm{PV}=$ present value 


\section{Table 5}

Single persons, initial wealth, present value of earnings, annuities, and consumption, and excess wealth, (thousands 2004\$)

\begin{tabular}{lrrrrrrrr}
\hline & $\mathrm{N}$ & $\begin{array}{r}\text { percent } \\
\text { positive }\end{array}$ & $\begin{array}{r}\text { mean } \\
\text { initial } \\
\text { wealth }\end{array}$ & $\begin{array}{r}\text { mean PV } \\
\text { of future } \\
\text { earnings }\end{array}$ & $\begin{array}{r}\text { mean PV } \\
\text { annuities }\end{array}$ & $\begin{array}{r}\text { mean PV } \\
\text { consumption }\end{array}$ & $\begin{array}{r}\text { mean } \\
\text { excess } \\
\text { wealth }\end{array}$ & $\begin{array}{r}\text { median } \\
\text { excess } \\
\text { wealth }\end{array}$ \\
\cline { 2 - 9 }$<$ high-school & 164 & 44.9 & 60.2 & 5.9 & 108.1 & 201.2 & -32.2 & -7.7 \\
High-school & 248 & 67.7 & 232.2 & 13.8 & 191.9 & 257.2 & 145.1 & 72.6 \\
Some college & 132 & 64.9 & 317.5 & 20.0 & 221.9 & 349.2 & 152.9 & 94.8 \\
College & 89 & 74.9 & 538.2 & 44.3 & 331.2 & 487.5 & 294.1 & 202.3 \\
All & 633 & 62.2 & 248.4 & 17.4 & 196.0 & 294.3 & 121.7 & 51.1 \\
\hline
\end{tabular}

Source: Authors' calculations. Note: PV = present value

Table 6

Percent of married persons adequately prepared: 95 to 100 percent chance of dying with positive wealth

\begin{tabular}{lrrrr}
\hline & $\mathrm{N}$ & All & Males & Females \\
\hline Less than high-school & 187 & 70.6 & 71.4 & 69.9 \\
High-school & 474 & 81.4 & 79 & 82.7 \\
Some college & 223 & 81.2 & 78.5 & 82.6 \\
College and above & 208 & 85.6 & 84.4 & 86.6 \\
All & 1,092 & 80.3 & 78.6 & 81.4 \\
\hline
\end{tabular}

Source: Authors’ calculations.

Table 7

Percent of single persons adequately prepared:

95 to 100 percent chance of dying with positive wealth

\begin{tabular}{lrrrr}
\hline & $\mathrm{N}$ & All & Males & Females \\
\hline Less than high-school & 164 & 39.6 & 66.7 & 32.8 \\
High-school & 248 & 64.1 & 69.8 & 62.2 \\
Some college & 132 & 59.1 & 62.5 & 58.0 \\
College and above & 89 & 65.2 & 65.0 & 65.2 \\
All & 633 & 56.9 & 66.9 & 53.8 \\
\hline
\end{tabular}

Source: Authors' calculations 
Table 8

Percent of married persons adequately prepared Chances are 5 percent or less that household would need to reduce consumption by more than 15 percent

\begin{tabular}{lrrrr}
\hline & $\mathrm{N}$ & All & Males & Females \\
\hline Less than high-school & 187 & 75.4 & 76.2 & 74.8 \\
High-school & 474 & 87.8 & 87.7 & 87.8 \\
Some college & 223 & 87.9 & 84.8 & 89.6 \\
College and above & 208 & 90.9 & 89.6 & 92.0 \\
All & 1,092 & 86.3 & 85.3 & 86.9 \\
\hline
\end{tabular}

Source: Authors' calculations

Table 9

Percent of single persons adequately prepared. Chances are 5 percent or less that household would need to reduce consumption by more than 15 percent

\begin{tabular}{lrrrr}
\hline & $\mathrm{N}$ & All & Males & Females \\
\hline Less than high-school & 164 & 47.6 & 66.7 & 42.7 \\
High-school & 248 & 73.4 & 77.8 & 71.9 \\
Some college & 132 & 65.9 & 71.9 & 64.0 \\
College and above & 89 & 76.4 & 70.0 & 78.3 \\
All & 633 & 65.6 & 73.0 & 63.3 \\
\hline
\end{tabular}

Source: Authors' calculations

Table 10

Percent of married persons adequately prepared: 95 to 100 percent chance of dying with positive wealth no health spending shocks

\begin{tabular}{rrrrrr}
\hline all & males & females & all & males & females \\
\hline 70.6 & 71.4 & 69.9 & 66.3 & 65.5 & 67.0 \\
81.4 & 79 & 82.7 & 77.2 & 74.7 & 78.5 \\
81.2 & 78.5 & 82.6 & 74.9 & 70.9 & 77.1 \\
85.6 & 84.4 & 86.6 & 83.7 & 82.3 & 84.8 \\
80.3 & 78.6 & 81.4 & 76.1 & 73.9 & 77.5 \\
\hline
\end{tabular}

Source: Authors’ calculations. 
Table 11

Percent of single persons adequately prepared: 95 to 100 percent chance of dying with positive wealth

\begin{tabular}{lrrrrrr}
\hline & \multicolumn{3}{c}{ no health spending shocks } & \multicolumn{3}{c}{ health spending shocks } \\
\cline { 2 - 7 } & all & males & females & all & males & females \\
\hline Less than high-school & 39.6 & 66.7 & 32.8 & 29.3 & 66.7 & 19.8 \\
High-school & 64.1 & 69.8 & 62.2 & 54.4 & 65.1 & 50.8 \\
Some college & 59.1 & 62.5 & 58.0 & 50.0 & 56.2 & 48.0 \\
College and above & 65.2 & 65.0 & 65.2 & 58.4 & 65.0 & 56.5 \\
All & 56.9 & 66.9 & 53.8 & 47.6 & 63.5 & 42.7 \\
\hline
\end{tabular}

Source: Authors’ calculations.

Table 12

Percent of married persons adequately prepared: Chances are 5 percent or less that household would need to reduce consumption by more than 15 percent

\begin{tabular}{lrrrrrr}
\hline & \multicolumn{3}{c}{ no health spending shocks } & \multicolumn{3}{c}{ health spending shocks } \\
\cline { 2 - 7 } & all & males & females & all & males & females \\
\cline { 2 - 7 } Less than high-school & 75.4 & 76.2 & 74.8 & 69.5 & 69.0 & 69.9 \\
High-school & 87.8 & 87.7 & 87.8 & 81.9 & 79.0 & 83.3 \\
Some college & 87.9 & 84.8 & 89.6 & 82.1 & 81.0 & 82.6 \\
College and above & 90.9 & 89.6 & 92.0 & 88.9 & 87.5 & 90.2 \\
All & 86.3 & 85.3 & 86.9 & 81.1 & 79.3 & 82.3 \\
\hline
\end{tabular}

Source: Authors’ calculations.

\section{Table 13}

Percent of single persons adequately prepared: Chances are 5 percent or less that household would need to reduce consumption by more than 15 percent

\begin{tabular}{lrrrrrr}
\hline & \multicolumn{3}{c}{ no health spending shocks } & \multicolumn{3}{c}{ health spending shocks } \\
\cline { 2 - 7 } & all & males & females & all & males & females \\
\cline { 2 - 6 } Less than high-school & 47.6 & 66.7 & 42.7 & 37.8 & 66.7 & 30.5 \\
High-school & 73.4 & 77.8 & 71.9 & 66.1 & 73.0 & 63.8 \\
Some college & 65.9 & 71.9 & 64.0 & 56.8 & 65.6 & 54.0 \\
College and above & 76.4 & 70.0 & 78.3 & 69.7 & 70.0 & 69.6 \\
All & 65.6 & 73.0 & 63.3 & 57.3 & 69.6 & 53.6 \\
\hline
\end{tabular}

Source: Authors’ calculations. 
Table 14

Estimated regression of log out-of-pocket spending on health care in 2005 MCBS. Married persons

\begin{tabular}{lrr}
\hline & Coefficient & std error \\
\hline Intercept & 2.91 & 0.25 \\
logOOP04 & 0.54 & 0.04 \\
male & 0.11 & 0.20 \\
age70-74 & -1.09 & 0.26 \\
age75-79 & -0.46 & 0.28 \\
age80+ & -0.62 & 0.26 \\
high school & 0.32 & 0.24 \\
some college & 1.03 & 0.30 \\
college or more & 1.32 & 0.29 \\
male X logOOP04 & -0.02 & 0.03 \\
age70-74 X logOOP04 & 0.17 & 0.04 \\
age75-79 X logOOP04 & 0.08 & 0.04 \\
age80+ X logOOP04 & 0.13 & 0.04 \\
high school X logOOP04 & -0.03 & 0.03 \\
some college X logOOP04 & -0.12 & 0.04 \\
college X logOOP04 & -0.15 & 0.04 \\
\hline Note: logOOP04 is log out-of-pocket spending in 2004 \\
\hline
\end{tabular}


Table 15

Estimated regression of log out-of-pocket spending on health care in 2005 MCBS. Single persons

\begin{tabular}{lrr}
\hline & coefficient & std error \\
\hline Intercept & 2.09 & 0.30 \\
logOOP04 & 0.67 & 0.05 \\
male & 0.27 & 0.24 \\
age70-74 & 0.12 & 0.38 \\
age75-79 & -0.42 & 0.36 \\
age80-84 & -0.13 & 0.34 \\
age85+ & -0.21 & 0.33 \\
high school & 0.67 & 0.23 \\
some college & 0.53 & 0.34 \\
college or more & 0.61 & 0.36 \\
male X logOOP04 & -0.05 & 0.03 \\
age7074 X logOOP04 & -0.03 & 0.06 \\
age7579 X logOOP04 & 0.07 & 0.05 \\
age8084 X logOOP04 & 0.05 & 0.05 \\
age8599 X logOOP04 & 0.07 & 0.05 \\
high school X logOOP04 & -0.08 & 0.03 \\
some college X logOOP04 & -0.05 & 0.05 \\
college X logOOP04 & -0.05 & 0.05 \\
\hline Note: logOOP04 is log out-of-pocket spending in 2004 \\
\hline
\end{tabular}




\section{Table 16}

Percent of married persons adequately prepared: 95 to 100 percent chance of dying with positive wealth. Health care spending shocks with and without serially correlated health care spending

\begin{tabular}{lrrrrrr}
\hline & \multicolumn{3}{c}{ no serial correlation } & \multicolumn{3}{c}{ serial correlation } \\
\cline { 2 - 7 } & all & males & females & all & males & females \\
\cline { 2 - 7 } Less than high-school & 66.3 & 65.5 & 67.0 & 64.2 & 65.5 & 63.1 \\
High-school & 77.2 & 74.7 & 78.5 & 73.6 & 71.6 & 74.7 \\
Some college & 74.9 & 70.9 & 77.1 & 73.1 & 70.9 & 74.3 \\
College and above & 83.7 & 82.3 & 84.8 & 80.8 & 81.2 & 80.4 \\
All & 76.1 & 73.9 & 77.5 & 73.3 & 72.4 & 73.8 \\
\hline
\end{tabular}

Source: Authors’ calculations.

\section{Table 17}

Percent of single persons adequately prepared: 95 to 100 percent chance of dying with positive wealth Health care spending shocks with and without serially correlated health care spending

\begin{tabular}{lrrrrrr}
\hline & \multicolumn{3}{c}{ no serial correlation } & \multicolumn{3}{c}{ serial correlation } \\
\cline { 2 - 7 } & all & males & females & all & males & females \\
\cline { 2 - 7 } Less than high-school & 29.3 & 66.7 & 19.8 & 24.4 & 60.6 & 15.3 \\
High-school & 54.4 & 65.1 & 50.8 & 49.6 & 63.5 & 44.9 \\
Some college & 50.0 & 56.2 & 48.0 & 47.7 & 56.2 & 45.0 \\
College and above & 58.4 & 65.0 & 56.5 & 58.4 & 65.0 & 56.5 \\
All & 47.6 & 63.5 & 42.7 & 43.9 & 61.5 & 38.6 \\
\hline
\end{tabular}

Source: Authors’ calculations. 